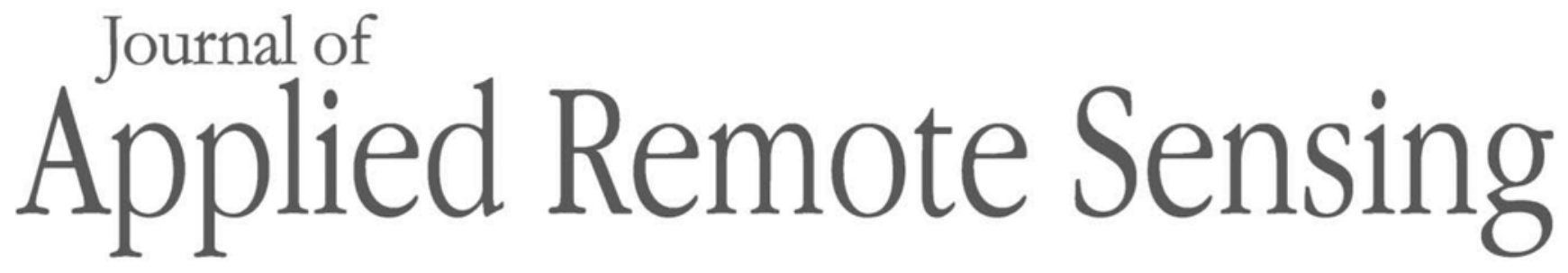

RemoteSensing.SPIEDigitalLibrary.org

\title{
Slope algorithm to map algal blooms in inland waters for Landsat 8/ Operational Land Imager images
}

Igor Ogashawara

Lin $\mathrm{Li}$

Max Jacobo Moreno-Madriñán 


\title{
Slope algorithm to map algal blooms in inland waters for Landsat 8/Operational Land Imager images
}

\author{
Igor Ogashawara, ${ }^{\mathrm{a}, *}$ Lin Li, ${ }^{\mathrm{a}}$ and Max Jacobo Moreno-Madriñán ${ }^{\mathrm{b}}$ \\ ${ }^{a}$ Indiana University-Purdue University Indianapolis, Department of Earth Sciences, \\ 723 West Michigan Street, SL118, Indianapolis, Indiana 46202, United States \\ ${ }^{b}$ Indiana University-Purdue University Indianapolis, Fairbanks School of Public Health, \\ Department of Environmental Health, 1050 Wishard Boulevard, Floors 5 and 6, Indianapolis, \\ Indiana 46202, United States
}

\begin{abstract}
Monitoring algal blooms using traditional methods is expensive and labor intensive. The use of satellite technology can attenuate such limitations. A common problem associated with the application of such technology is the need to eliminate the effects of atmosphere, which can be, at least, a time-consuming task. Thus, a remote sensed algal bloom monitoring system needs a simple algorithm which is nonsensitive to atmospheric correction and that could be applied to small aquatic systems. A slope algorithm $\left(\mathrm{SA}_{\text {red-NIR }}\right)$ was developed to detect and map the extension of algal blooms using the Landsat 8/Operational Land Imager. SA red-NIR $_{\text {was }}$ shown to have advantages over other commonly used indices to monitor algal blooms, such as normalized difference vegetation index (NDVI), normalized difference water index, and floating algae index. $\mathrm{SA}_{\text {red-NIR }}$ was shown to be less sensitive to different atmospheric corrections, less sensitive to thin clouds, and less susceptible to confusion when classifying water and moderate bloom conditions. Based on ground truth data from Eagle Creek Reservoir, Indiana, $\mathrm{SA}_{\text {red-NIR }}$ showed an accuracy of $88.46 \%$ while NDVI only showed a $46.15 \%$ accuracy. Finally, based on qualitative and quantitative results, $\mathrm{SA}_{\text {red-NIR }}$ can be used as a tool to improve the governance of small size water resources. (C) 2016 Society of Photo-Optical Instrumentation Engineers (SPIE) [DOI: 10 .1117/1.JRS.11.012005]
\end{abstract}

Keywords: inland water algal blooms; bloom identification; water quality; bio-optical algorithms.

Paper 16579SS received Jul. 31, 2016; accepted for publication Dec. 5, 2016; published online Dec. 28, 2016.

\section{Introduction}

Algal blooms, especially cyanobacteria harmful algal blooms (CHABs), have been a big concern for environmental and public health managers. ${ }^{1}$ The impacts range from simple esthetic issues related to color, taste, and odor to the production of dangerous toxins, known as cyanotoxins. ${ }^{2}$ A large CHAB occurred in the summer of 2014 in the western region of Lake Erie, Ohio, and resulted in a cyanotoxin contamination in the tap water of Toledo, Ohio, affecting over 500,000 people. ${ }^{3}$

CHABs are a big concern worldwide due to their fast growth rate ${ }^{4}$ and their capacity to produce cyanotoxins. ${ }^{1}$ Human contamination is often reported, but its identification is difficult since the symptoms are usually masked as a typical gastrointestinal disease. In aquatic systems, especially in those used for water supply, it is very important to monitor algal blooms to adjust treatment methods appropriately. Traditional algal bloom monitoring methods are labor intensive and costly since they are based on a collection of field samples, laboratory analysis, and manual cell counts. ${ }^{5}$ Additionally, because of the spatial and temporal heterogeneity of water bodies, the characterization of algal blooms is usually inadequate since it relies on interpolation and extrapolation among the sampled points. ${ }^{6}$ Satellite imagery provides spatial and temporal coverage with

*Address all correspondence to: Igor Ogashawara, E-mail: igorogas@iupui.edu

$1931-3195 / 2016 / \$ 25.00$ (C) 2016 SPIE

Journal of Applied Remote Sensing

012005-1

Jan-Mar 2017 • Vol. 11(1) 
low cost for analysis and can be used as a tool to monitor water quality and algal blooms. An example of this use is the "Experimental Lake Erie Harmful Algal Bloom Bulletin" developed by the National Oceanic and Atmospheric Administration, which uses satellite imagery as a prediction tool for algal blooms. The use of remote sensing is also emphasized by $\mathrm{Kutser}^{8}$ who stated that the use of remote sensing to provide information about the extent of algal blooms is more reliable if compared to traditional monitoring methods, because it does not physically break (or disturb) the algal bloom when collecting data. This statement agreed with Metsamaa et al. ${ }^{9}$ who described remote sensing as the only technique able to map the spatial distribution of algal blooms.

The moderate-resolution imaging spectroradiometer (MODIS) and medium resolution imaging spectrometer (MERIS) are the most commonly used remote sensors for monitoring water quality. ${ }^{10}$ However, because of their moderate spatial resolution, 1000 and $300 \mathrm{~m}$ respectively, it is not possible to monitor water quality from small aquatic systems or to detect spatial variability within them. The most recent satellite from the Landsat family (Landsat 8) carries the Operational Land Imager (OLI) sensor, which is a nine band push broom imager with eight channels at 30-m spatial resolution. ${ }^{11}$ This spatial resolution combined with the global data availability makes OLI an important sensor for the monitoring of worldwide aquatic systems. ${ }^{12,13}$ Although OLI presents a better spatial resolution when compared to MODIS and MERIS, OLI's temporal resolution is not appropriate for an operational monitoring once algal blooms quickly respond to changes in the environment. Therefore, OLI can be used to map algal bloom extension. The use of sensors such as MODIS and MERIS, which have a higher temporal resolution, are appropriated in areas where spatial resolution is not an issue and/or there is a need to create a time series of the obsevervations. ${ }^{14,15}$ Another important issue was highlighted by $\mathrm{Hu}^{16}$ who observed that indices commonly used for algal blooms identification were influenced by the atmosphere. Therefore, an algorithm that can map the extension of algal blooms without being influenced by the atmospheric correction used has a considerably advantage.

In this research, the overall goal was to assess the potential of the OLI sensor to map the extension of algal blooms by subdividing them in three classes: severe bloom, moderate bloom, and water. The specific objectives of this research are: (1) to compare and evaluate the performance of several existing reflectance-based indices to map the extension of algal blooms using Landsat 8/OLI spectral bands, (2) to develop a bio-optical algorithm using Landsat 8/OLI sensor that is able to perform consistently when applied to images subjected to different atmospheric corrections, and (3) to test the capability of such an algorithm to map algal blooms in three classes (severe bloom, moderate bloom, and water) using Landsat 8/OLI data.

\section{Background}

\subsection{Monitoring Algal Blooms with Landsat Family}

Remote sensing has been considered an efficient approach for the investigation of inland waters. The feasibility of the Landsat satellites family to estimate water quality properties has been recently studied by several researchers. ${ }^{17-22}$ The algorithms developed in these studies are divided here into two groups: empirical and semiempirical following the classification proposed by Ogashawara. ${ }^{23}$

Landsat 4-5 Thematic Mapper (TM) and Landsat 7 Enhanced Thematic Mapper Plus $\left(\mathrm{ETM}^{+}\right)$were used by Vincent et al. ${ }^{17}$ and Sun et al. ${ }^{18}$ to estimate phycocyanin (PC)—a unique pigment of inland water cyanobacteria—via an empirical algorithm. Vincent et al. ${ }^{17}$ using one $\mathrm{TM}$ and one $\mathrm{ETM}^{+}$image over the western part of Lake Erie and developed an empirical algorithm based on forward and backward stepwise linear regression and on its highest value for the coefficient of determination $\left(R^{2}\right)$. This study showed that a combination of TM and $\mathrm{ETM}^{+}$bands centered at $485,660,835$, and $2220 \mathrm{~nm}$ produced the highest $R^{2}$ when related to PC concentrations. Sun et al. ${ }^{18}$ developed an empirical algorithm based on the data from two cruises in Lake Dianchi, China, and the radiometric data from the blue, green, red, and near-infrared (NIR) channels from Landsat family imagery. Through a multivariate regression, the authors found the best performance (mean absolute percentage error $<10 \%$ ) with the use of a combination among 
coefficients and 10 independent variables (single bands or band ratios). Oyama et al., ${ }^{19}$ using the spectral bands in the blue, red, and NIR, and developed a spectral decomposition algorithm to estimate chlorophyll- $a$ (chl- $a$ ) and nonalgal particles (NAP) concentrations from Lake Kasumigaura, Japan. This algorithm is based on the combination of these spectral bands and the use of decomposition coefficients (one for phytoplankton and one for NAP concentrations). Its applicability is restricted due to the need of some assumptions, such as (i) the need for preliminary information about the phytoplankton and NAP, (ii) the need for standard reflectance spectra from different optically active constituents present in the water column, [i.e., chl- $a$, NAP, and colored dissolved organic matter (CDOM)], and (iii) the need for a corresponding estimation model must exist.

Dalu et al..$^{20}$ applied a semiempirical algorithm to estimate chl- $a$ from TM images based on the remote sensing reflectance $\left(R_{\mathrm{rs}}\right)$ values at blue, green, and red bands. Recently, Ogashawara, ${ }^{23}$ using TM and $\mathrm{ETM}^{+}$, evaluated the use of different semiempirical indices commonly used to map CHABs and aquatic macrophytes in inland water. The indices used were the normalized difference vegetation index (NDVI) ${ }^{24}$ the normalized difference water index (NDWI) ${ }^{25}$ and the floating algal index (FAI). ${ }^{16}$ Oyama et al. ${ }^{21}$ calculated, for each index, different thresholds to map three different classes: cyanobacteria, macrophytes, and water. They observed NDWI as the best to distinguish cyanobacteria and macrophytes while NDVI was the best to classify water. Manzo et al. ${ }^{22}$ simulated OLI spectra based on the data collected from three Italian lakes (Garda, Mantua, and Trasimeno). The simulated bands were used to evaluate the sensitivity of each spectral band to different optical active compounds-chl- $a$, suspended particulate matter, and CDOM. All these studies showed that there is a need for using the spatial resolution from the Landsat family satellites for the spatial analysis of algal blooms, especially in small aquatic systems. Thus, the continuity of the Landsat family is important not only for the spatial analysis but also to have a continuous archive of data, which can be used to understand the past in order to predict the future.

\subsection{Monitoring Algal Blooms With Red-Near-Infrared Algorithms}

Red-NIR bio-optical algorithms have been used for detecting and monitoring algal blooms in inland waters. Although these algorithms used spectral bands located in the red and NIR channels, their mathematical structures are different (Table 1) and these differences can lead to different estimations. The most common structure is a ratio between NIR and red, usually known as a two-band algorithm. ${ }^{26}$ A variation of this algorithm is the use of a second NIR spectral band, where reflectance is minimally affected by other optically active constituents. ${ }^{27}$ This structure is known as a three-band model. Another algorithm that also uses three spectral bands was proposed by Wynne et al. ${ }^{28}$ and is known as the spectral shape (SS) algorithm, which calculates a base line between red and NIR bands and adds a second red spectral band to evaluate its height in comparison to the base line. Most recently, Mishra and Mishra ${ }^{29}$ presented a normalized difference chlorophyll index (NDCI) that normalizes the difference between the NIR and red bands.

Table 1 Structure of red and NIR bio-optical algorithms.

\begin{tabular}{|c|c|c|}
\hline Type & Reference & Structure \\
\hline Two band & Moses et al. ${ }^{26}$ & $\frac{R_{\mathrm{rs}}(\mathrm{NIR})}{R_{\mathrm{rs}}(\mathrm{Red})}$ \\
\hline Three band & Dall'Olmo and Gitelson. ${ }^{27}$ & $\frac{1}{R_{\mathrm{rs}}(\mathrm{Red})-R_{\mathrm{rs}}\left(\mathrm{NIR}_{1}\right)} \cdot R_{\mathrm{rs}}\left(\mathrm{NIR}_{2}\right)$ \\
\hline $\mathrm{NDCl}$ & Mishra and Mishra ${ }^{29}$ & $\frac{R_{\mathrm{rs}}(\mathrm{NIR})-R_{\mathrm{rs}}(\mathrm{Red})}{R_{\mathrm{rs}}(\mathrm{NIR})+R_{\mathrm{rs}}(\mathrm{Red})}$ \\
\hline SS & Wynne et al. ${ }^{28}$ & $\begin{array}{r}R_{\mathrm{rs}}\left(\operatorname{Red}_{2}\right)-R_{\mathrm{rs}}\left(\operatorname{Red}_{1}\right)-\left[R_{\mathrm{rs}}(\mathrm{NIR})\right. \\
\left.-R_{\mathrm{rs}}\left(\operatorname{Red}_{1}\right)\right] \cdot \frac{\lambda\left(\operatorname{Red}_{2}\right)-\lambda\left(\operatorname{Red}_{1}\right)}{\lambda(\mathrm{NIR})+\lambda\left(\operatorname{Red}_{1}\right)}\end{array}$ \\
\hline
\end{tabular}


Studies have been comparing the performance of existing semiempirical bio-optical algorithms for the estimation of algal blooms. Gurlin et al. ${ }^{30}$ compared the performance of two ${ }^{26}$ and three-band algorithms ${ }^{27}$ using MERIS spectral bands. The study showed that the two-band algorithm estimated chl- $a$ with a mean absolute error (MAE) of $2.3 \mathrm{mg} \mathrm{m}^{-3}$ when the concentrations ranged from 0 to $100 \mathrm{mg} \mathrm{m}^{-3}$, whereas the three-band algorithm produced an MAE of $2.5 \mathrm{mg} \mathrm{m}^{-3}$ for the same concentration range. For a lower range, from 0 to $25 \mathrm{mg} \mathrm{m}^{-3}$, the two-band algorithm produced an MAE of $1.2 \mathrm{mg} \mathrm{m}^{-3}$ while the MAE was $1.9 \mathrm{mg} \mathrm{m}^{-3}$ for the three-band algorithm. Augusto-Silva et al. ${ }^{31}$ compared the performance of these two algorithms and added to the analysis the NDCI. ${ }^{29}$ The comparison was conducted using in situ surface spectroradiometer measurements in an inland tropical reservoir. This study showed similar results compared to Gurlin et al., ${ }^{30}$ where the two-band algorithm outperformed the three-band algorithm. However, in Augusto-Silva's study, NDCI showed the best performance among the three algorithms. While the normalized root-mean-square error (NRMSE) for the two-band model was $18.32 \%$, NDCI produced an NRMSE of $17.85 \%$. Recently, Beck et al. ${ }^{32}$ compared 12 bio-optical algorithms used for the estimation of chl- $a$ concentrations using the spectral bands of different sensors. The authors concluded that NDCI is the most widely applicable algorithm and performs well for the following sensors: WorldView-2, Sentinel-2, Landsat 8, MODIS, and Sentinel-3. Based on these comparisons, it was observed that a simple band ratio and NDCI showed the best performance among several chl- $a$ algorithms. However, it was also observed that there is no algorithm that uses the slope between the red and NIR spectral bands.

\section{Materials and Methods}

\subsection{Remote Sensing Data}

For the algorithm development, OLI images at level 1 (Table 2) and atmospherically corrected products for the western part of Lake Erie were acquired on 2014 Julian days August 1, 2014, September 18, 2014, and November 5, 2014, over West Lake Erie, near the city of Toledo, Ohio, and those for Lake Tai, China, on October 26, 2014, were downloaded from the Earth Explorer website.

These different dates were selected to characterize different algal blooms in the western part of Lake Erie, Ohio. This region of Lake Erie has an average depth of $19 \mathrm{~m}$ and during the summers it has recurring harmful algal blooms (HABs) due to its morphology and mainly due to anthropogenic inputs of nutrients from farming. ${ }^{3}$ On August 1, 2014, an algal bloom occurred and caused the shutdown of the water supply in Toledo, Ohio, as described by Paerl et al. $^{3}$ For September 18, 2014, and November 5, 2014, there was no reported bloom

Table 2 Image identifier, WRS-2 path and row, and date for the OLI and TM images used in this research.

\begin{tabular}{lcc}
\hline \hline Image & WRS-2 tile path-row & Date \\
\hline LC80200312014213LGN00 & P020 - R031 & August 1, 2014 \\
LC80200312014261LGN00 & P020-R031 & September 18, 2014 \\
LC80200312014309LGN00 & P020-R031 & November 5, 2014 \\
LC81190382014299LGN00 & P119-R038 & October 26, 2014 \\
LT50210322006166GNC01 & P021-R032 & June 15, 2006 \\
LT50210322006182GNC01 & P021-R032 & July 1, 2006 \\
LT50220322006189GNC01 & P022 - R032 & July 8, 2006 \\
LT50220322006205GNC01 & P022 - R032 & July 24, 2006 \\
\hline \hline
\end{tabular}


in the region, thus these images were used use as an example of a no bloom event. Figure 1 presents the location of Lake Erie as well as the location of three regions of interest (ROIs): the first one shows a severe bloom location [Fig. 1(d)], the second one shows severe bloom (solid dark red pixels) and moderate bloom (cloudy pink pixels) locations [Fig. 1(e)], and the third one shows clouds over the water [Fig. 1(f)]. These ROIs were used to evaluate the performance of the existing indices and the proposed algorithm to map the extension of algal blooms. Figure 1 presents the location of the study sites used in this research in the Midwest of the United States: Eagle Creek Reservoir, Indiana [Fig. 1(b)], and the western part of Lake Erie, Ohio [Fig. 1(c)].

For validation purposes, we used a Landsat 8/OLI image acquired on October 26, 2014, over Lake Tai, China, and four Landsat TM images acquired between June and July 2006 over Eagle Creek Reservoir, Indiana (Table 2). Lake Tai was selected because of its frequent and serious algal blooms, mainly related to CHABs. Lake Tai is the third largest lake in China and has a surface area around $2338 \mathrm{~km}^{2}$. Algal blooms in this aquatic system are usually related to nutrient level rise, which has been increasing since 1980s. ${ }^{5}$ Figure 2 presents the location of Lake Tai, China, as well as the ROI red square within the RGB false color composite. In addition, four Landsat TM images of Eagle Creek Reservoir, central Indiana were selected because of the availability of ground truth chl- $a$ concentration data, which was used to classify bloom severity based on Ohio Environmental Protection Agency (Ohio EPA) HAB Response Strategy. ${ }^{33}$ Eagle Creek Reservoir is one of the major supplies of drinking water for central Indiana and it frequently experiences CHABs.

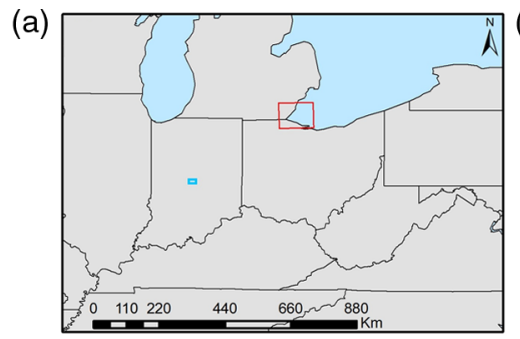

(b)

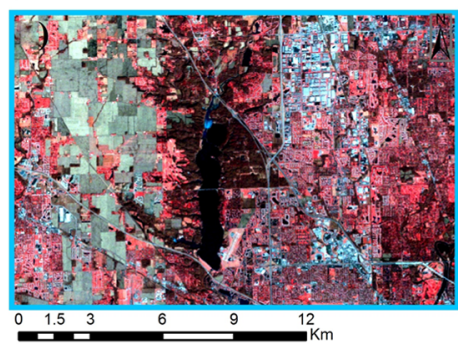

(c)

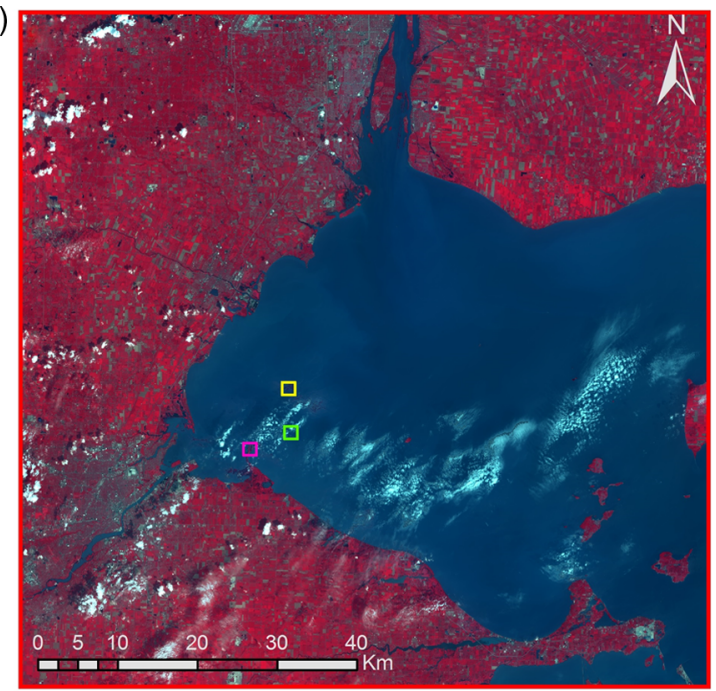

(d)

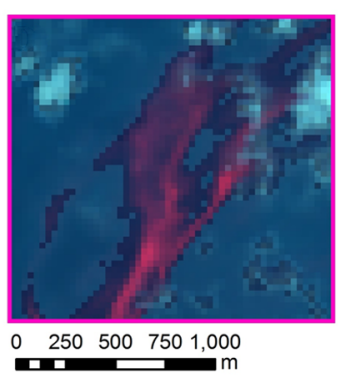

(e)

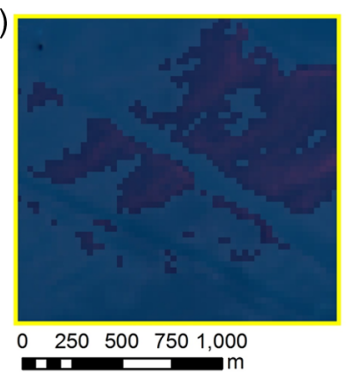

(f)

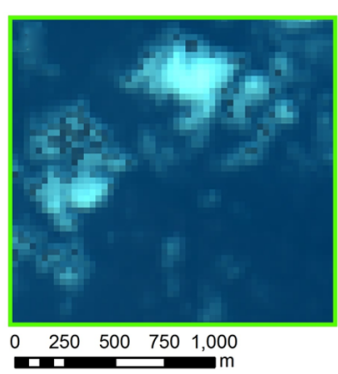

Fig. 1 Location of the areas used to evaluate the algorithms: (a) location of Lake Erie and Eagle Creek Reservoir, (b) false color $(R=$ band $4, G=$ band 3 , and $B=$ band 2) Landsat $5 / T M$ composite for Eagle Creek Reservoir, (c) false color $(R=$ band $5, G=$ band 4 , and $B=$ band 3 ) Landsat $8 / \mathrm{OLI}$ composite for West Lake Erie with the locations of the three ROls, (d) ROI 1, (e) ROI 2, (f) ROI 3. 


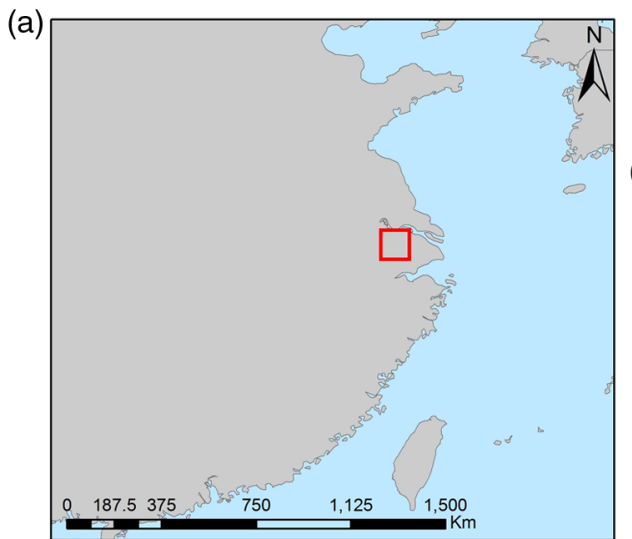

(c)

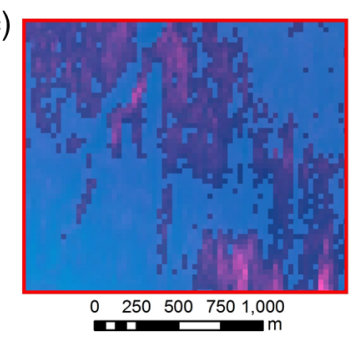

(b)

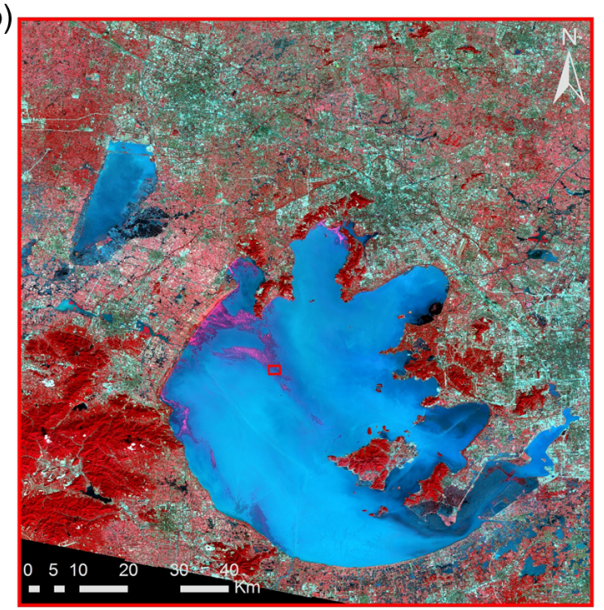

Fig. 2 Location of the area used to evaluate the algorithms: (a) location of Lake Tai, China, (b) false color $(R=$ band $5, G=$ band 4 , and $B=$ band 3 ) composite for Lake Tai with location of the interested area, and (c) ROI from Lake Tai.

\subsection{Atmospheric Calibration}

To assess the sensitivity of different remote sensing indices commonly used for mapping algal blooms to atmospheric effects, we used the selected OLI images, which were atmospherically corrected using two different approaches: a complex and a simple atmospheric correction. The complex approach is the provisional land surface reflectance product (PLSRP), which is prepared and released as part of the Landsat 8 Surface Reflectance Climate Data Record by the United States Geological Survey (USGS). This provisional product is generated using L8SR, a complex, physically based radiative transfer atmospheric correction algorithm different from the $6 \mathrm{~S}$ algorithm with the latter being used to generate the land surface reflectance product for Landsat 4-5 $\mathrm{TM}$ and Landsat $7 \mathrm{ETM}^{+} .{ }^{34} \mathrm{~L} 8 \mathrm{SR}$ uses a series of meteorological and environmental parameters, such as pressure, water vapor, air temperature, digital elevation model (DEM), ozone, aerosol optical thickness, and other sensor-derived parameters.

The second approach is dark object subtraction (DOS), a simple image-based atmospheric correction algorithm. This algorithm was proposed by $\mathrm{Chavez}^{35}$ and it is based on the assumptions that within an image, there are dark pixels in which the radiance is only originated from atmospheric scattering. When the radiance of the dark pixel is subtracted from all other pixels, we remove the contribution of atmosphere. To perform the DOS, we first calculate the spectral radiance $\left(L_{\lambda}\right)$ in $\left(\mathrm{W} \mathrm{m}^{-2} \mathrm{sr}^{-1} \mu \mathrm{m}^{-1}\right)$ from digital number (DN) based on OLI product description. $^{36}$

To remove the dark pixel value, we followed the procedure presented by Vincent et al. ${ }^{17}$ to identify the dark pixel, which is based on removing the second darkest pixel (second lowest radiance value)

$$
L_{\mathrm{p}}=L_{\text {dark }}-\frac{0.01 \times \mathrm{ESUN}_{\lambda} \times \cos \theta}{\left(\pi \times d^{2}\right)},
$$

where $L_{\mathrm{p}}$ is the path radiance, $L_{\text {dark }}$ is the radiance of the second darkest object in the histogram, ESUN is the mean solar exoatmospheric irradiances, $\theta$ is the solar zenith angle in degrees, and 
$d$ is the Earth-Sun distance in astronomical units. ESUN for OLI can be calculated ${ }^{37}$ using its metadata file from the image as follows:

$$
\text { ESUN }=\left(\pi \times d^{2}\right) \times \frac{\text { Radiance maximum }}{\text { Reflectance maximum }} .
$$

Therefore, the surface reflectance was finally calculated as

$$
\rho=\frac{\left[\pi \times\left(L_{\lambda}-L_{\mathrm{p}}\right) \times d^{2}\right]}{(\mathrm{ESUN} \times \cos \theta)} .
$$

Since DOS is only based on DN values of each spectral band, it is useful for operational purposes because of its simplicity, especially when atmospheric parameters are not available to feed the physically-based atmospheric correction algorithms, such as the PLSRP.

\subsection{Water Classes}

It is possible to identify three major algal bloom classifications: severe bloom, moderate bloom, and water. The identification and mapping of three classes are essential for environmental monitoring programs, which can use the geoinformation about moderate blooms to create mitigation strategies for water quality management. According to the Ohio EPA HAB Response Strategy, ${ }^{33}$ severe bloom is characterized by the presence of a thick scum of algal blooms over the water surface, a cyanobacteria cell count higher than 100,000 cells $/ \mathrm{mL}$, presence of cyanotoxins, biovolume higher than $10 \mathrm{~mm}^{3} / \mathrm{L}$, and chl- $a$ concentration higher than $50 \mu \mathrm{g} / \mathrm{L}$. A moderate bloom is visible in the water column, but has no scums on the surface, has a cyanobacteria cell count between 10,000 and 100,000 cells/mL, has a biovolume between 1 and $10 \mathrm{~mm}^{3} / \mathrm{L}$, and a chl $a$ concentration between 5 and $50 \mu \mathrm{g} / \mathrm{L}$.

Based on these descriptions, the moderate blooms are important in the public health management perspective since no cyanotoxin is detected; therefore, in this stage, the algal bloom is not harmful. The spatial identification of blooms helps environmental and public health managers to prepare adaptive strategies for the presence of algal blooms. An example for each class

(a)

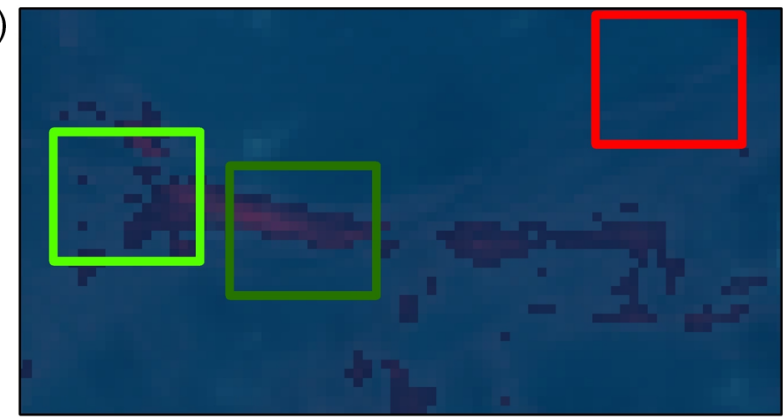

(b)

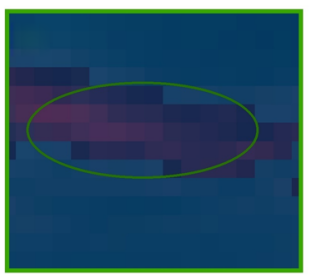

Severe bloom (c)

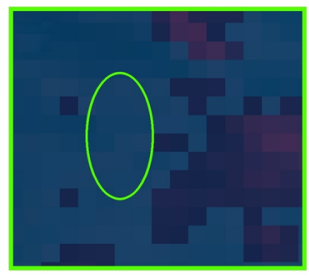

Moderate bloom

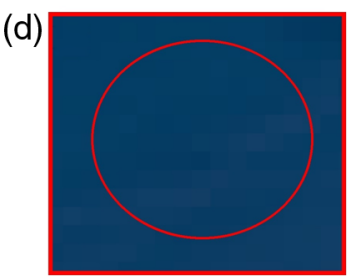

Water

Fig. 3 Different water classes for algal bloom monitoring using an $R G B$ false color composite $(R=$ band $5, G=$ band 4 , and $B=$ band 3 ). (a) Three classes in this area of the RGB composed image, (b) severe bloom area, thick scum of algae which appears as red-purple area, (c) moderate bloom area, thin scum of algae in the surface which appears as a thin pinkish cloud surrounding the bloom pixels in the image, and (d) water area, no presence of blooms usually appears as blue in the image. 
Ogashawara, Li, and Moreno-Madriñán: Slope algorithm to map algal blooms in inland waters...

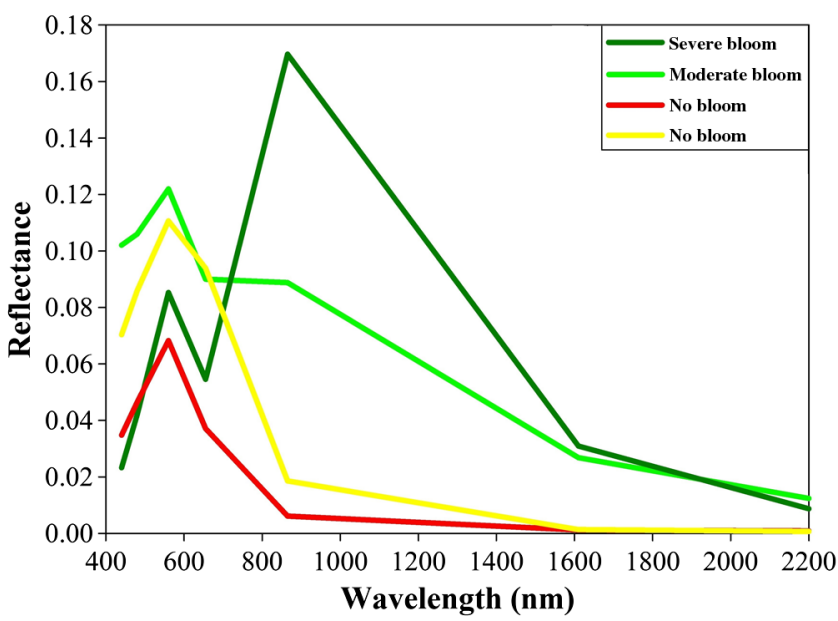

Fig. 4 Average irradiance reflectance from PLSRP for pixels classified as severe bloom (dark green) from the product from August 1, 2014, moderate bloom (light green) from the product from August 1, 2014, and no bloom (red and yellow) conditions from the products from September 18, 2014, and November 5, 2014.

in an RGB false color composite of the Landsat 8/OLI image from August 1, 2014, over the western portion of Lake Erie is shown in Fig. 3.

\subsection{Algorithm Development}

For the development of the algorithm, surface reflectance from PLSRPs for August 1, 2014, September 18, 2014, and November 5, 2014, was used to calculate the average irradiance reflectance spectra for severe bloom, moderate bloom, and water classes (Fig. 4). The PLSRP product was chosen because of its robust atmospheric correction, which provides an irradiance reflectance spectra better suited for the algorithm development. The average irradiance reflectance spectra were extracted from these three PLSRPs in the proximity of the Toledo City's water intake in Lake Erie, Ohio $\left(41^{\circ} 42^{\prime} 7^{\prime \prime} \mathrm{N}, 83^{\circ} 15^{\prime} 41^{\prime \prime} \mathrm{W}\right)$. The average spectra sensed from the image of August 1, 2014, identified conditions of severe bloom (dark green) and moderate bloom (light green), while that of September 18, 2014, and November 5, 2014, did not show any bloom conditions (red and yellow lines). We observed that the slope between bands 4 (red, $655 \mathrm{~nm}$ ) and 5 (NIR, $865 \mathrm{~nm}$ ) is positive for severe bloom conditions (dark green line) due to the high absorption of chl- $a$ in the red region of the spectrum and high scattering of algal cells in the NIR region. The slope is almost neutral for moderate bloom conditions (light green line) because of average absorption of chl- $a$ and a medium scattering of algal cells. The slope is negative for the no bloom cases, mainly caused by the high absorption of water and low scattering in the NIR region. This distinct pattern of the slope between red and NIR spectral bands led to the development of a slope algorithm $\left(\mathrm{SA}_{\text {red-NIR }}\right)$ to map the algal blooms' extension in inland waters.

Therefore, the slope algorithm proposed in this work can be described as follows:

$$
\mathrm{SA}_{\mathrm{red}-\mathrm{NIR}}=\left(\frac{R_{\mathrm{red}}-R_{\mathrm{NIR}}}{\lambda_{\mathrm{red}}-\lambda_{\mathrm{NIR}}}\right) \times 1000
$$

where $\mathrm{SA}_{\text {red-NIR }}=$ slope algorithm, $R_{\text {red }}=$ the irradiance reflectance on the OLI/band centered at $655 \mathrm{~nm}, R_{\mathrm{NIR}}=$ the irradiance reflectance on the OLI/band centered at $865 \mathrm{~nm}, \lambda_{\text {red }}=$ $655 \mathrm{~nm}$, and $\lambda_{\mathrm{NIR}}=865 \mathrm{~nm}$.

\subsubsection{Evaluation and comparison}

To evaluate the performance of the proposed algorithm, we used the Landsat 8/OLI image over the western part of Lake Erie, Ohio, on August 1, 2014. To evaluate the sensitivity to different atmospheric corrections approaches, $\mathrm{SA}_{\text {red-NIR }}$ was computed from products of both types of 
atmospheric correction: PLSRP and DOS. For each procedure, pixels from each class (severe bloom, moderate bloom, or water) were grouped to identify threshold values for each class. The classification based on the threshold values was analyzed via a qualitative analysis based on the visual comparison on ROIs areas. Quantitative analysis based on statistical discriminant analysis among the classes was computed using central tendency estimators and a Mann-Whitney pairwise test. In addition to the evaluation of $\mathrm{SA}_{\text {red-NIR }}$, the same methodology was applied to evaluate the commonly used indices to map the extension of algae blooms using the Landsat family (as described in Sec. 2.1): NDVI, ${ }^{24}$ NDWI,${ }^{25}$ and FAI. ${ }^{16}$ Results from all four algorithms were compared for both atmospheric correction products to determine which was the least affected by changes in the atmosphere. For the FAI, we did not apply the postatmospheric correction procedure (the calculation of Rayleigh-corrected reflectance) described by $\mathrm{Hu}^{16}$ since we were only interested in evaluating the responses of the algorithms for two different types of atmospheric correction: PLSRP and DOS.

\subsubsection{Validation}

The $\mathrm{SA}_{\text {red-NIR }}$ algorithm was applied to both a Landsat 8/OLI image from Lake Tai, China, (Fig. 2) and a Landsat 5/TM images from Eagle Creek Reservoir, Indiana, for validation. For Lake Tai, the algorithm was validated based on qualitative and quantitative analysis of the estimated classes and compared to the reference classes which were determined by using visual identification of pixels of severe and moderate blooms as well as water pixels. The validation was then computed via a confusion matrix between the reference (manually identified pixels) and the estimated classification based on the algorithm's thresholds. Due to the availability of in situ chl- $a$ concentrations for Eagle Creek Reservoir, the algorithm was validated based on the chl- $a$ concentration ranges for each class based on the Ohio EPA HAB Response Strategy. ${ }^{33}$

\section{Results and Discussion}

\subsection{Indices Performances}

The four indices (NDVI, NDWI, FAI, and $\mathrm{SA}_{\text {red-NIR }}$ ) were calculated for the Landsat 8/OLI image over the western part of Lake Erie during the bloom on August 1, 2014. Indices values were selected from pixels preclassified in one of the three classes: severe bloom, moderate bloom, and water (Fig. 3). The pixel selection for class 1 [pixels that covered severe bloom, Fig. 3(b)] contained 725 pixels, for class 2 [pixels with moderate bloom conditions, Fig. 3(c)] 945 sampling pixels, and class 3 [pixels with water, Fig. 3(d)] 1121 sampling pixels. Central tendency statistics (average, maximum, minimum, and standard variation) for each of the classes was compared to evaluate the discrepancy among the three classes for each index.

Table 3 presents central tendency statistics for each class calculated for each index using the PLSRP and suggested that for this atmospheric corrected approach, all indices were able to distinguish each class. However, it was also observed that FAI showed very small variations from class to class with average FAI values around 0.05, 0.07, and 0.06 for severe bloom,

Table 3 Central tendency statistics for each index and class using PLSRP. Classes are indicated by the number after each index $(1=$ severe bloom, $2=$ moderate bloom, and $3=$ water $)$.

\begin{tabular}{lcccccccccccc}
\hline \hline & NDVI1 & NDVI2 & NDVI3 & NDWI1 & NDWI2 & NDWI3 & FAl1 & FAI2 & FAI3 & SA1 & SA2 & SA3 \\
\hline Average & 0.491 & 0.053 & -0.196 & 0.741 & 0.577 & 0.247 & 0.050 & 0.072 & 0.062 & 0.613 & 0.047 & -0.111 \\
Max & 0.782 & 0.171 & -0.175 & 0.808 & 0.652 & 0.268 & 0.076 & 0.084 & 0.064 & 2.158 & 0.163 & -0.098 \\
Min & 0.298 & -0.076 & -0.211 & 0.550 & 0.384 & 0.222 & 0.041 & 0.064 & 0.059 & 0.224 & -0.053 & -0.121 \\
Std. dev. & 0.124 & 0.041 & 0.007 & 0.040 & 0.028 & 0.008 & 0.005 & 0.003 & 0.001 & 0.394 & 0.038 & 0.005 \\
\hline \hline
\end{tabular}


Ogashawara, Li, and Moreno-Madriñán: Slope algorithm to map algal blooms in inland waters...

Table 4 Central tendency statistics for each index and class using DOS. Classes are indicated by the number after each index ( $1=$ severe bloom, $2=$ moderate bloom, and $3=$ water $)$.

\begin{tabular}{lcccccccccccc}
\hline \hline & NDVI1 & NDVI2 & NDVI3 & NDWI1 & NDWI2 & NDWI3 & FAl1 & FAI2 & FAl3 & SA1 & SA2 & SA3 \\
\hline Average & 0.456 & 0.038 & -1.002 & 0.758 & 0.764 & -1.012 & 0.020 & 0.033 & 0.031 & 0.465 & 0.019 & -0.139 \\
Max & 0.785 & 0.258 & -0.908 & 0.872 & 0.935 & -0.763 & 0.043 & 0.045 & 0.034 & 1.886 & 0.133 & -0.127 \\
Min & 0.230 & -0.299 & -1.129 & 0.524 & 0.346 & -1.533 & -0.032 & 0.027 & 0.029 & 0.126 & -0.080 & -0.149 \\
Std. dev. & 0.136 & 0.087 & 0.032 & 0.059 & 0.073 & 0.101 & 0.011 & 0.003 & 0.001 & 0.349 & 0.037 & 0.005 \\
\hline \hline
\end{tabular}

moderate bloom, and water, respectively. Although the standard deviations for FAI and NDWI are lower than NDVI and $\mathrm{SA}_{\text {red-NIR }}$, the overlay between classes (based on the range for each class) is more common for FAI and NDWI. Therefore, NDVI and $\mathrm{SA}_{\text {red-NIR }}$ were shown to be the most appropriated for the identification of algal blooms in inland waters using the PLSRP.

Table 4 presents the central tendency statistics for each class calculated for each index using the DOS atmospheric correction approach. Even though DOS is a simple atmospheric correction approach, the results from its central tendency analysis proved to be consistent with the pattern shown for PLSRP in Table 3. In both types of corrections methods, NDVI and SA $\mathrm{red}_{\text {reNIR }}$ were shown to be the most appropriate indices for classifying algal blooms, while NDWI, in the image corrected with the DOS approach, showed a higher confusion between severe bloom and moderate bloom. It also stressed the similarity of the three classes when FAI was applied, with the average values being around $0.019,0.032$, and 0.031 for severe bloom, moderate bloom, and water classes, respectively. The confusion arising from the similarity in the maximum and minimum values for each class indicated the inability of FAI classes moderate bloom and water to set

Table 5 Probability of being the same from the Mann-Whitney pairwise test for the indices values.

\begin{tabular}{|c|c|c|c|c|c|c|c|}
\hline \multicolumn{4}{|c|}{ PLSRP } & \multicolumn{4}{|c|}{ DOS } \\
\hline \multicolumn{8}{|c|}{ NDVI } \\
\hline & Severe & Moderate & Water & & Severe & Moderate & Water \\
\hline Severe & - & $<0.0001$ & $<0.0001$ & Severe & - & $<0.0001$ & $<0.0001$ \\
\hline Moderate & $<0.0001$ & - & 0 & Moderate & $<0.0001$ & - & 0 \\
\hline Water & $<0.0001$ & 0 & - & Water & $<0.0001$ & 0 & - \\
\hline \multicolumn{8}{|c|}{ NDWI } \\
\hline & Severe & Moderate & Water & & Severe & Moderate & Water \\
\hline Severe & - & $<0.0001$ & $<0.0001$ & Severe & - & 0.1780 & $<0.0001$ \\
\hline Moderate & $<0.0001$ & - & 0 & Moderate & 0.1780 & - & 0 \\
\hline Water & $<0.0001$ & 0 & - & Water & $<0.0001$ & 0 & - \\
\hline \multicolumn{8}{|c|}{$S A_{\text {red-NIR }}$} \\
\hline & Severe & Moderate & Water & & Severe & Moderate & Water \\
\hline Severe & - & $<0.0001$ & $<0.0001$ & Severe & - & $<0.0001$ & $<0.0001$ \\
\hline Moderate & $<0.0001$ & - & 0 & Moderate & $<0.0001$ & - & 0 \\
\hline Water & $<0.0001$ & 0 & - & Water & $<0.0001$ & 0 & - \\
\hline
\end{tabular}

Note: Bold values indicate high similarity. 
Ogashawara, Li, and Moreno-Madriñán: Slope algorithm to map algal blooms in inland waters...

Table 6 Thresholds adopted for algal bloom classification.

\begin{tabular}{lccc}
\hline \hline & Severe bloom & Moderate bloom & Water \\
\hline NDVI & $>0.2$ & From -0.15 to 0.2 & $<-0.15$ \\
$\mathrm{SA}_{\text {red-NIR }}$ & $>0.15$ & From -0.05 to 0.15 & $<-0.05$ \\
Color of the class & Dark green & Light green & Dark blue \\
\hline \hline
\end{tabular}

up fixed thresholds to differentiate moderate bloom from water pixels. Therefore, we exclude FAI from the follow up analysis.

Similarities among the classes and indices values were analyzed via the nonparametric Mann-Whitney $\mathrm{U}$ pairwise $\operatorname{est}^{38}$ to statistically assess the performance of each index (Table 5). For this test, the results (Table 5) are given in the $p$-value, for the null hypothesis that the two populations are the same. Thus, a low $p$-value indicates that we reject the null hypothesis and accept the alternative hypothesis that the compared populations are not the same. In Table 5, each of the classes was distinguished by the four indices calculated with PLSRP using the nonparametric Mann-Whitney U pairwise test. However, when the indices were calculated using the DOS atmospheric correction, severe bloom and moderate bloom classes were similar in the case of the NDWI index. Thus, the NDWI calculated using the simplistic DOS approach for atmospheric correction generated confusion, which corroborates to the hypothesis that some indices depend on the atmospheric correction used. These results show that a simple atmospheric correction decreased the accuracy for classifying a severe bloom, which is the only class that presents scum on the surface. The inability of NDWI to differentiate some classes when using a DOS atmospheric correction (Table 5) and the impossibility to create thresholds for the values of FAI when using PLSRP or DOS (Tables 3 and 4) justifies the use of NDVI and $\mathrm{SA}_{\text {red-NIR }}$ to map the algal blooms extension.

NDVI and $\mathrm{SA}_{\text {red-NIR }}$ were shown to be consistent in their results for identifying the three classes during an algal bloom. Therefore, to use NDVI and $\mathrm{SA}_{\text {red-NIR }}$ to classify algal blooms, thresholds were developed for each of the indices. Table 6 shows the thresholds calculated for NDVI and $\mathrm{SA}_{\text {red-NIR }}$ to perform the image classification, as well as the respective colors for each class in the final classification.

\subsection{Classification Evaluation for West Lake Erie, Ohio}

The three ROIs within the western part of Lake Erie, Ohio, [Figs. 1(c), 1(d), and 1(e)] were used to evaluate the performance of the NDVI and $\mathrm{SA}_{\text {red-NIR }}$ in the classification of algal blooms. NDVI and $\mathrm{SA}_{\text {red-NIR }}$ were applied to the PLSRP and DOS atmospheric corrected images and were compared to the false color Landsat 8/OLI RGB composite $(\mathrm{R}=$ band $5, \mathrm{G}=$ band 4 , and $\mathrm{B}=$ band 3). Figure 5 shows the application of both indices to ROI 1 from the western part of Lake Erie. Figure 5(a) shows the false color RGB composite for a part of the algal bloom that affected the water supply in Toledo City, Ohio, during summer $2014 .^{3}$ The severe bloom appears

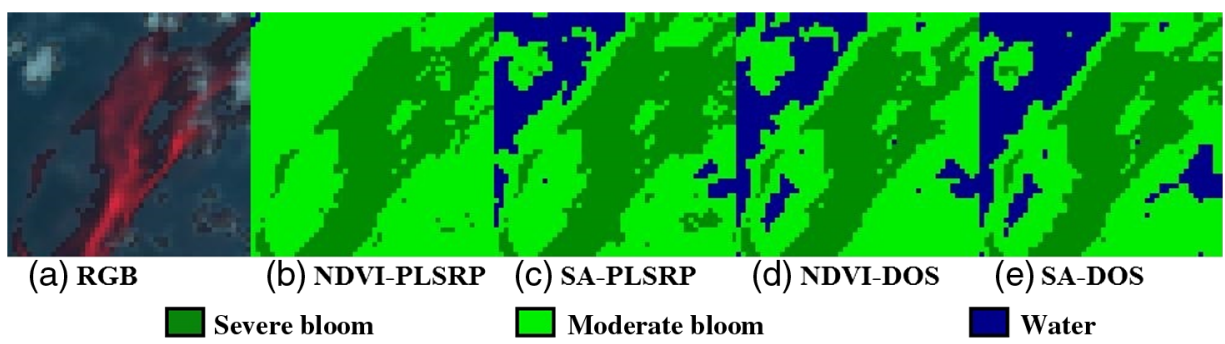

Fig. 5 (a) False color $(R=$ band $5, G=$ band 4, and $B=$ band 3) composite over ROI 1 from West

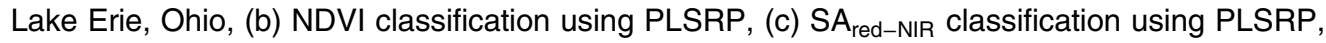
(d) NDVI classification using DOS atmospheric corrected images, and (e) SA $\mathrm{A}_{\text {red-NIR }}$ classification using DOS atmospheric corrected images. 
in red, moderate bloom pixels are indicated by the pinkish color (smooth pink), and blue is related to nonbloom pixels, which are essentially water. Figure 5(b) shows the result from the NDVI classification of the PLSRP, while Fig. 5(d) shows the result from the NDVI classification of the DOS atmospheric correction product. A comparison between the two NDVI classification results [Figs. 5(b) and 5(d)] and the reference [Fig. 5(a)] shows a better discrimination among the three classes of interest when DOS is used to calculate the NDVI. In contrast, the NDVI calculated with PLSRP overestimated the area of moderate bloom conditions as compared with the results from the NDVI of the DOS product [Fig. 5(d)]. Figures 5(c) and 5(e) show the application of $\mathrm{SA}_{\text {red-NIR }}$ to the same area, and $\mathrm{SA}_{\text {red-NIR }}$ resulted in a similar algal bloom classification for both atmospheric correction products. Moreover, similar to the NDVI, the use of the PLSRP led to overestimation of the moderate bloom area as compared to the use of the DOS product. Based on this qualitative analysis, we observed a better identification of water classes when $\mathrm{SA}_{\text {red-NIR }}$ was used. Comparing the two atmospheric corrections, the DOS showed a better performance since it could distinguish moderate bloom from water, while the PLSRP was only able to distinguish it when $\mathrm{SA}_{\text {red-NIR }}$ was used.

ROI 2 was selected to asses if NDVI and $\mathrm{SA}_{\text {red-NIR }}$ were able to identify a water track crossing the algal bloom as shown in Fig. 6(a). Similarly to the previous results, the NDVI calculated using the PLSRP overestimated the moderate bloom pixels and underestimated the water pixels [Fig. 6(b)]. However, the use of DOS atmospheric corrected images for NDVI did not result in such over- and underestimation [Fig. 6(d)]. For $\mathrm{SA}_{\text {red-NIR }}$, the results were similar for both atmospheric correction approaches and led to the detection of the water track crossing the algal bloom [Figs. 6(c) and 6(d)]. Thus, the NDVI was shown to be more susceptible to variations in the atmospheric correction, while the $\mathrm{SA}_{\text {red-NIR }}$ consistently identified the differences between moderate bloom and water for both atmospheric correction methods.

Figure 7 shows a sensitivity test for both NDVI and $\mathrm{SA}_{\text {red-NIR }}$ to distinguish cloud cover from severe blooms. The ROI 3 is placed over an area in which clouds were present [Fig. 7(a)] and the application of the NDVI calculated using the PLSRP [Fig. 7(b)] showed that the cloud cover was misclassified as moderate bloom for most of the area of ROI 3. The NDVI calculated using DOS

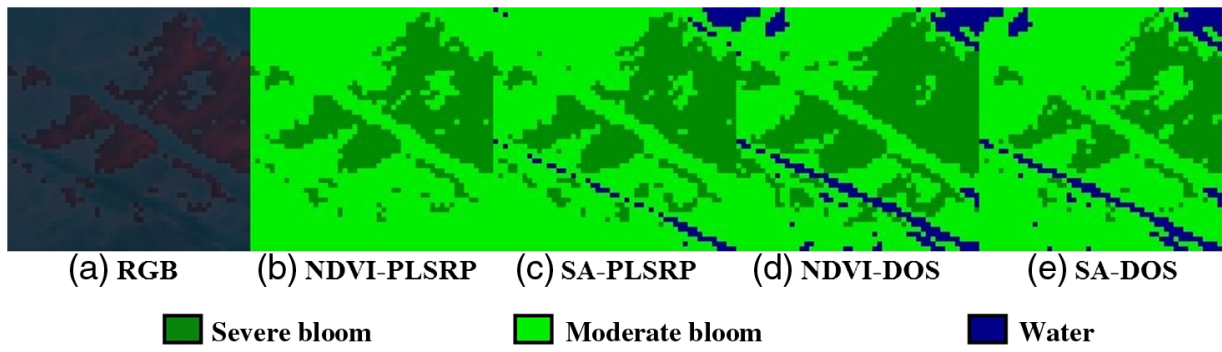

Fig. 6 (a) False color ( $\mathrm{R}=$ band $5, \mathrm{G}=$ band 4 , and $\mathrm{B}=$ band 3 ) composite over $\mathrm{ROI} 2$ from West Lake Erie, Ohio, (b) NDVI classification using PLSRP, (c) $S_{\text {red-NIR }}$ classification using PLSRP, (d) NDVI classification using DOS atmospheric corrected images, and (e) $\mathrm{SA}_{\text {red-NIR }}$ classification using DOS atmospheric corrected images.

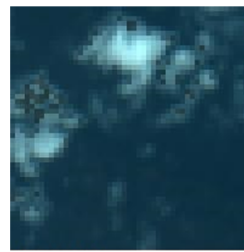

(a) RGB

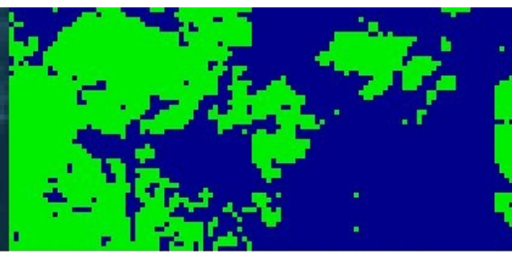

(b) NDVI-PLSRP (c) SA-PLSRP

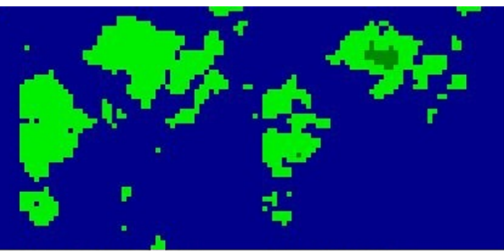

(d) NDVI-DOS (e) SA-DOS

Severe bloom

Moderate bloom

Fig. 7 (a) False color $(R=$ band $5, G=$ band 4 , and $B=$ band 3 ) composite over $R O I$ from West Lake Erie, Ohio, (b) NDVI classification using PLSRP, (c) $\mathrm{SA}_{\text {red-NIR }}$ classification using PLSRP, (d) NDVI classification using DOS atmospheric corrected images, and (e) $\mathrm{SA}_{\text {red-NIR }}$ classification using DOS atmospheric corrected images. 
[Fig. 7(c)] also misclassified clouds as moderate bloom conditions; however, the area of this misclassification is much smaller than the one calculated using PLSRP [Fig. 7(b)]. $\mathrm{SA}_{\text {red-NIR }}$ performed similarly when applied to the two atmospheric correction approaches [Figs. 7(c) and 7(e)] with the exception that when used to classify the DOS corrected image [Fig. 7(e)] part of the cloud was misclassified as severe bloom. Nevertheless, it is already known that the use of optical remote sensing is limited to the cloud cover of the image. Once again, $\mathrm{SA}_{\text {red-NIR }}$ was shown to be consistent between the two atmospheric correction products and was not sensitive to thin clouds. Overall, these qualitative results indicate that $\mathrm{SA}_{\text {red-NIR }}$ is a better option to map algal blooms because it is consistent between both atmospheric correction approaches, less sensitive to thin clouds, and led to less confusion in the classification of water and moderate conditions. However, both the NDVI and $\mathrm{SA}_{\text {red-NIR }}$ with either atmospheric correction misclassified thick clouds. Moreover, these results also indicate that NDVI performed better when applied to the DOS product than to the PLSRP. Overall the PLSRP was shown to distinguish severe blooms better than DOS; however, in most cases, it was unable to distinguish moderate blooms from water. Because of this, the simple atmospheric correction was shown to outperform the complex one, since it was able to distinguish the three classes.

To quantitatively evaluate the performances of NDVI and $\mathrm{SA}_{\text {red-NIR }}$ in mapping algal blooms, we computed the confusion matrix among all sampling pixels. Table 7 shows the results of the confusion matrix for the NDVI and $\mathrm{SA}_{\text {red-NIR }}$ calculated using both atmospheric correction approaches. The confusion matrix results, $\mathrm{SA}_{\text {red-NIR }}$ and NDVI, showed similar accuracies in both atmospheric corrections approaches. Thus, based on the quantitative analysis for the western part of Lake Erie, both indices were able to classify algal blooms with a higher accuracy. If compared to the qualitative analysis, the indices performances were not significantly different.

Table 7 Confusion matrix for NDVI and $\mathrm{SA}_{\text {red-NIR }}$ for both atmospheric corrections approaches.

\begin{tabular}{|c|c|c|c|c|c|}
\hline \multicolumn{6}{|c|}{ PLSRP } \\
\hline NDVI & & Severe & Moderate & Water & Accuracy \\
\hline & Severe & 725 & 0 & 0 & 0.9857 \\
\hline & Moderate & 0 & 905 & 40 & \\
\hline & Water & 0 & 0 & 1121 & \\
\hline \multirow[t]{4}{*}{$\mathrm{SA}_{\text {red-NIR }}$} & & Severe & Moderate & Water & Accuracy \\
\hline & Severe & 725 & 0 & 0 & 0.9996 \\
\hline & Moderate & 5 & 939 & 1 & \\
\hline & Water & 0 & 0 & 1121 & \\
\hline \multicolumn{6}{|c|}{ DOS } \\
\hline \multirow[t]{4}{*}{ NDVI } & & Severe & Moderate & Water & Accuracy \\
\hline & Severe & 725 & 0 & 0 & 0.9889 \\
\hline & Moderate & 13 & 914 & 18 & \\
\hline & Water & 0 & 0 & 1121 & \\
\hline \multirow[t]{4}{*}{$\mathrm{SA}_{\text {red-NIR }}$} & & Severe & Moderate & Water & Accuracy \\
\hline & Severe & 698 & 27 & 0 & 0.9900 \\
\hline & Moderate & 0 & 944 & 1 & \\
\hline & Water & 0 & 0 & 1121 & \\
\hline
\end{tabular}

Note: Bold values indicate the accuracy for confusion matrix. 


\subsection{Classification Validation for Lake Tai, China}

As previously explained, Lake Tai, China, was chosen to assess the performance in another study area, due to the frequent cyanobacteria blooms occurring in the aquatic system. Qualitative results from Lake Tai, China, showed similar patterns as those observed in the western part of Lake Erie, Ohio. Figure 8 shows the application of both indices for the ROI within Lake Tai, whose results were similar to those found in the western part of Lake Erie, Ohio. It also showed that the NDVI using PLSRP overestimates the moderate bloom class and

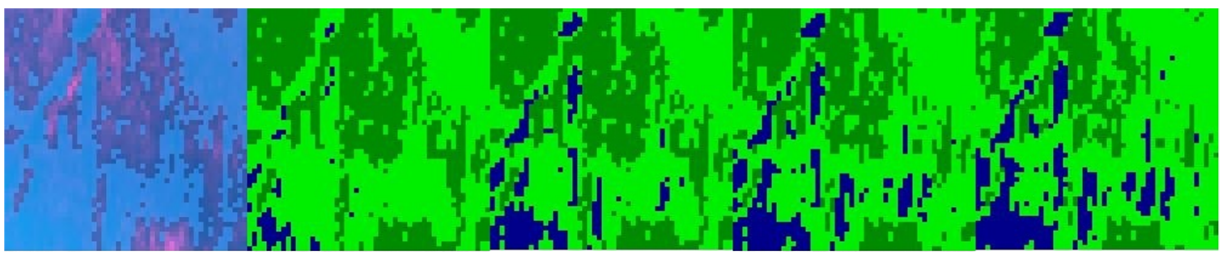
(a) RGB
(b) NDVI-PLSRP
(c) SA-PLSRP
(d) NDVI-DOS
(e) SA-DOS
Severe bloom
Moderate bloom
Water

Fig. 8 (a) False color $(R=$ band $5, G=$ band 4, and $B=$ band 3 ) composite over the ROI from Lake Tai, China, (b) NDVI classification using PLSRP, (c) SA red-NIR classification using PLSRP, (d) NDVI classification using DOS atmospheric corrected images, and (e) $\mathrm{SA}_{\text {red-NIR }}$ classification using DOS atmospheric corrected images.

Table 8 Confusion matrix for NDVI and $\mathrm{SA}_{\text {red-NIR }}$ for both atmospheric corrections approaches.

\begin{tabular}{|c|c|c|c|c|c|}
\hline \multicolumn{6}{|c|}{ PLSRP } \\
\hline NDVI & & Severe & Moderate & Water & Accuracy \\
\hline & Severe & 715 & 0 & 0 & 1.000 \\
\hline & Moderate & 0 & 361 & 0 & \\
\hline & Water & 0 & 0 & 1324 & \\
\hline \multirow[t]{4}{*}{$S A_{\text {red-NIR }}$} & & Severe & Moderate & Water & Accuracy \\
\hline & Severe & 715 & 0 & 0 & 0.9900 \\
\hline & Moderate & 20 & 337 & 4 & \\
\hline & Water & 0 & 0 & 1324 & \\
\hline \multicolumn{6}{|c|}{ DOS } \\
\hline \multirow[t]{4}{*}{ NDVI } & & Severe & Moderate & Water & Accuracy \\
\hline & Severe & 704 & 11 & 0 & 0.9883 \\
\hline & Moderate & 12 & 272 & 5 & \\
\hline & Water & 0 & 0 & 1324 & \\
\hline \multirow[t]{4}{*}{$\mathrm{SA}_{\text {red-NIR }}$} & & Severe & Moderate & Water & Accuracy \\
\hline & Severe & 702 & 13 & 0 & 0.9912 \\
\hline & Moderate & 0 & 353 & 8 & \\
\hline & Water & 0 & 0 & 1324 & \\
\hline
\end{tabular}

Note: Bold values indicate the accuracy for confusion matrix. 
underestimates the water class. Similarly to previous results, NDVI using the DOS atmospheric corrected image performed better than NDVI using PLSRP. SA red-NIR $_{\text {results were consistent }}$ with those obtained from Lake Erie. This suggests a better performance of $\mathrm{SA}_{\text {red-NIR }}$ as compared with NDVI in two different geographic regions.

To quantify the performance from both indices, we computed the confusion matrix among the three classes (Table 8) for Lake Tai. Such quantification drew similar results to those found in the western part of Lake Erie with the accuracy being not significantly different for both indices. Similarly, these results suggested a better performance of the $\mathrm{SA}_{\text {red-NIR }}$ algorithm when compared to the NDVI algorithm as well as a better performance of DOS when compared to PLSRP.

Table 9 Chl-a concentrations, EPA classification (reference), and estimated classes from NDVI and $\mathrm{SA}_{\text {red-NIR. }}$.

\begin{tabular}{|c|c|c|c|c|}
\hline Sampling point & Chl-a ( $\mu \mathrm{g} / \mathrm{L})$ & EPA classification & $S A_{\text {red-NIR }}$ & NDVI \\
\hline $0606-502$ & 24.53 & Moderate bloom & Moderate bloom & Severe bloom \\
\hline $0606-503$ & 23.63 & Moderate bloom & Moderate bloom & Severe bloom \\
\hline 0606-504 & 25.8 & Moderate bloom & Moderate bloom & Severe bloom \\
\hline $0606-506$ & 21.9 & Moderate bloom & Severe bloom & Severe bloom \\
\hline $0606-511$ & 24.2 & Moderate bloom & Moderate bloom & Moderate bloom \\
\hline $0606-514$ & 25.28 & Moderate bloom & Moderate bloom & Severe bloom \\
\hline $0606-517$ & 23.72 & Moderate bloom & Moderate bloom & Severe bloom \\
\hline $0606-520$ & 23.31 & Moderate bloom & Moderate bloom & Moderate bloom \\
\hline $0606-521$ & 27.38 & Moderate bloom & Moderate bloom & Severe bloom \\
\hline 0606-552 & 21.7875 & Moderate bloom & Moderate bloom & Moderate bloom \\
\hline $0606-553$ & 30.8625 & Moderate bloom & Moderate bloom & Severe bloom \\
\hline $0606-554$ & 35.4375 & Moderate bloom & Moderate bloom & Severe bloom \\
\hline $0606-555$ & 32.55 & Moderate bloom & Moderate bloom & Severe bloom \\
\hline $0606-560$ & 8.7375 & Moderate bloom & Moderate bloom & Severe bloom \\
\hline $0606-561$ & 8.1375 & Moderate bloom & Moderate bloom & Severe bloom \\
\hline $0607-611$ & 30.6 & Moderate bloom & Moderate bloom & Moderate bloom \\
\hline $0607-612$ & 8.33 & Moderate bloom & Moderate bloom & Moderate bloom \\
\hline $0607-613$ & 24.68 & Moderate bloom & Moderate bloom & Moderate bloom \\
\hline $0607-614$ & 14.93 & Moderate bloom & Moderate bloom & Moderate bloom \\
\hline $0607-615$ & 24.93 & Moderate bloom & Moderate bloom & Moderate bloom \\
\hline $0607-616$ & 11.85 & Moderate bloom & Moderate bloom & Moderate bloom \\
\hline $0607-617$ & 25.2 & Moderate bloom & Moderate bloom & Moderate bloom \\
\hline 0607-618 & 46.2 & Moderate bloom & Moderate bloom & Moderate bloom \\
\hline 0607-619 & 41.31 & Moderate bloom & Moderate bloom & Moderate bloom \\
\hline $0607-620$ & 47.18 & Moderate bloom & Severe bloom & Severe bloom \\
\hline $0607-621$ & 70.35 & Severe bloom & Moderate bloom & Moderate bloom \\
\hline
\end{tabular}

Note: Boldface indicates the discrepancy from the reference. 
Ogashawara, Li, and Moreno-Madriñán: Slope algorithm to map algal blooms in inland waters...

\subsection{Validation for Eagle Creek Reservoir, Indiana}

Ground truth data were also used to assess the indices comparison. For this purpose, Landsat images were acquired concomitant to the field collection for Eagle Creek Reservoir, Indiana. Chl- $a$ concentrations were collected for each sample. Chl- $a$ concentration was used as the reference for the algal bloom classifications; chl- $a$ concentrations varied from 8.1375 to $70.35 \mu \mathrm{g} / \mathrm{L}$. $\mathrm{SA}_{\text {red-NIR }}$ and NDVI classes for each pixel corresponding to the field samples were also classified and the results were presented in Table 9. The results showed an accuracy of $88.46 \%$ and $46.15 \%$ for $\mathrm{SA}_{\text {red-NIR }}$ and NDVI, respectively. As shown in Table 9, the NDVI overestimates the classification of severe bloom areas, with a confusion between moderate and severe bloom classes.

Based on the results from qualitative and quantitative analysis from these three study sites, $\mathrm{SA}_{\text {red-NIR }}$ was shown to outperform other indices in the identification and mapping of algal blooms. These results show that $\mathrm{SA}_{\text {red-NIR }}$ can be a useful tool for analysis of time series of Landsat family data and web tools, which could be used to connect society and academia in order to promote a better governance of small size water resources.

\section{Conclusions}

A simple slope algorithm $\left(\mathrm{SA}_{\text {red-NIR }}\right)$ is introduced to map the extension of algal blooms in inland waters using 30-m spatial resolution data from Landsat TM and OLI sensors. The $\mathrm{SA}_{\text {red-NIR}}$, defined as the slope between irradiance reflectance from red and NIR, is an effective approach to detect and map the extension of algal blooms using different atmospheric correction algorithms. Compared to NDVI, NDWI, and FAI, the SA $\mathrm{A}_{\text {red-NIR }}$ was better able to identify the occurrence of algal blooms with a Landsat 8/OLI image in the presence of thin clouds. Such ability gives to $\mathrm{SA}_{\text {red-NIR }}$ an advantage over the other indices. In addition, due to the spatial resolution of OLI, $\mathrm{SA}_{\text {red-NIR }}$ could be used as a powerful tool for monitoring algal blooms in inland waters, which are usually smaller than the spatial resolutions of other satellite sensors (MODIS/Aqua, MODIS/Terra, and VIIRS/NPP). If combined with previous Landsat sensors $\left(\mathrm{TM}\right.$ and $\left.\mathrm{ETM}^{+}\right), \mathrm{SA}_{\text {red-NIR }}$ could be used to establish a time series of algal bloom occurrence in different aquatic systems worldwide. Therefore, several applications to improve the water governance and consequently public and environmental health could be developed using $\mathrm{SA}_{\text {red-NIR }}$.

\section{Acknowledgments}

The authors thank the USGS for collecting, archiving, processing, and distributing Landsat 8/ OLI data. I.O. thanks the IndianaView Consortium Educational for the scholarship.

\section{References}

1. K. Sivonen and G. Jones, "Cyanobacterial toxins," in Toxic Cyanobacteria in Water: A Guide to Their Public Health Consequences, Monitoring and Management, I. Chorus and J. Bartram, Eds., pp. 55-124, UNESCO/WHO/UNEP, London, UK (1999).

2. G. A. Codd et al., "Harmful cyanobacteria," in Harmful Cyanobacteria, J. Huisman, H. C. P. Matthijs, and P. M. Visser, Eds., pp. 1-23, Springer, Dordrecht, the Netherlands (2005).

3. H. W. Paerl et al., "Algal blooms: noteworthy nitrogen," Science 346(6206), 175 (2014).

4. S. Mishra, D. R. Mishra, and W. M. Schluchter, "A novel algorithm for predicting phycocyanin concentrations in cyanobacteria: a proximal hyperspectral remote sensing approach," Remote Sens. 1, 758-775 (2009).

5. C. Le et al., "Remote sensing of phycocyanin pigment in highly turbid inland waters in Lake Taihu, China," Int. J. Remote Sens. 32, 8253-8269 (2011).

6. S. Khorram et al., "Water quality mapping of Augusta Bay, Italy from Landsat-TM data," Int. J. Remote Sens. 12, 803-808 (1991).

7. National Oceanic and Atmospheric Administration, "Experimental Lake Erie harmful algal bloom bulletin,” 2016, http://www2.nccos.noaa.gov/coast/lakeerie/bulletin/bulletin_current .pdf (20 November 2016). 
Ogashawara, Li, and Moreno-Madriñán: Slope algorithm to map algal blooms in inland waters...

8. T. Kutser, "Quantitative detection of chlorophyll in cyanobacterial blooms by satellite remote sensing," Limnol. Oceanogr. 49, 2179-2189 (2004).

9. L. Metsamaa, T. Kutser, and N. Strombeck, "Recognising cyanobacterial blooms based on their optical signature: a modelling study," Boreal Environ. Res. 11, 493-506 (2006).

10. W. J. Moses et al., "Estimation of chlorophyll-a concentration in case II waters using MODIS and MERIS data—successes and challenges," Environ. Res. Lett. 4, 045005 (2009).

11. J. R. Irons, J. L. Dwyer, and T. A. Barsi, "The next Landsat satellite: the Landsat data continuity mission," Remote Sens. Environ. 122, 11-21 (2012).

12. L. C. Smith et al., "Disappearing Arctic lakes," Science 308(5727), 1429 (2005).

13. J. Li and Y. Sheng, "An automated scheme for glacial lake dynamics mapping using Landsat imagery and digital elevation models: a case study in the Himalayas," Int. J. Remote Sens. 33, 5194-5213 (2012).

14. I. Ogashawara et al., "Performance analysis of MODIS 500-m spatial resolution products for estimating chlorophyll-a concentrations in oligo- to meso-trophic waters case study: Itumbiara Reservoir, Brazil,” Remote Sens. 6, 1634-1653 (2014).

15. I. Ogashawara and M. J. Moreno-Madriñán, "Improving environmental health management through remotely sensed water quality monitoring," ISPRS Int. J. Geoinf. 3, 1234-1255 (2014).

16. C. Hu, "A novel ocean color index to detect floating algae in the global oceans," Remote Sens. Environ. 113, 2118-2129 (2009).

17. R. K. Vincent et al., "Phycocyanin detection from LANDSAT TM data for mapping cyanobacterial blooms in Lake Erie," Remote Sens. Environ. 89, 381-392 (2004).

18. D. Sun et al., "Estimating phycocyanin pigment concentration in productive inland waters using Landsat measurements: a case study in Lake Dianchi," Opt. Express 23(3), 30563074 (2015).

19. Y. Oyama et al., "Testing the spectral decomposition algorithm (SDA) for different phytoplankton species by a simulation based on tank experiments," Int. J. Remote Sens. 31(6), 1605-1623 (2010).

20. T. Dalu et al., "An assessment of chlorophyll-a concentration spatio-temporal variation using Landsat satellite data, in a small tropical reservoir," Geocarto Int. 30(10), 11301143 (2015).

21. Y. Oyama, B. Matsushita, and T. Fukushima, "Distinguishing surface cyanobacterial blooms and aquatic macrophytes using Landsat/TM and ETM+ shortwave infrared bands," Remote Sen. Environ. 157, 35-47 (2015).

22. C. Manzo et al., "Sensitivity analysis of a bio-optical model for Italian lakes focused on Landsat-8, Sentinel-2 and Sentinel-3," Eur. J. Remote Sens. 48, 17-32 (2015).

23. I. Ogashawara, "Terminology and classification of bio-optical algorithms," Remote Sens. Lett. 6(8), 613-617 (2015).

24. J. W. Rouse et al., "Monitoring vegetation systems in the Great Plains with ERTS," in Proc. of the 3rd ERTS Symp. NASA SP-351, pp. 309-317, NASA, Washington, DC (1973).

25. B. C. Gao, "NDWI-A normalized difference water index for remote sensing of vegetation liquid water from space," Remote Sens. Environ. 58, 257-266 (1996).

26. W. J. Moses et al., "Satellite estimation of chlorophyll-a concentration using the red and NIR bands of MERIS-The Azov Sea case study," IEEE Geosci. Remote Sens. Lett. 6, 845-849 (2009).

27. G. Dall'Olmo and A. A. Gitelson, "Effect of bio-optical parameter variability on the remote estimation of chlorophyll-a concentration in turbid productive waters: experimental results," Appl. Opt. 44, 412-422 (2005).

28. T. T. Wynne et al., "Relating spectral shape to cyanobacterial blooms in the Laurentian Great Lakes," Int. J. Remote Sens. 29, 3665-3672 (2008).

29. S. Mishra and D. R. Mishra, "Normalized difference chlorophyll index: a novel model for remote estimation of chlorophyll-a concentration in turbid productive waters," Remote Sens. Environ. 117, 394-406 (2012).

30. D. Gurlin, A. A. Gitelson, and W. J. Moses, "Remote estimation of CHL-A concentration in turbid productive waters-return to a simple two-band NIR-red model?" Remote Sens. Environ. 115, 3479-3490 (2011). 
Ogashawara, Li, and Moreno-Madriñán: Slope algorithm to map algal blooms in inland waters...

31. P. B. Augusto-Silva et al., "Analysis of MERIS reflectance algorithms for estimating chlorophyll-a concentration in a Brazilian Reservoir," Remote Sens. 6, 11689-11707 (2014).

32. R. Beck et al., "Comparison of satellite reflectance algorithms for estimating chlorophylla in a temperate reservoir using coincident hyperspectral aircraft imagery and dense coincident surface observations," Remote Sens. Environ. 178, 15-30 (2016).

33. Ohio Environmental Protection Agency, "Public water system harmful algal bloom response strategy,” 2016, http://epa.ohio.gov/Portals/28/documents/habs/PWS_HAB_Response_ Strategy.pdf (20 November 2016).

34. United States Geological Survey (USGS), "Provisional LANDSAT 8 surface reflectance product," Department of the Interior, USGS, Washington, DC (2015).

35. P. S. Chavez, Jr., "An improved dark-object subtraction technique for atmospheric scattering correction of multispectral data," Remote Sens. Environ. 24(3), 459-479 (1988).

36. United States Geological Survey (USGS), "Using the USGS Landsat 8 product," 2013, https://landsat.usgs.gov/Landsat8_Using_Product.php (20 April 2015).

37. E. J. Tizado, "i.landsat.toar," 2014, http://grass.osgeo.org/grass64/manuals/i.landsat.toar. html (20 September 2016).

38. H. B. Mann and D. R. Whitney, "On a test of whether one of two random variables is stochastically larger than the other," Ann. Math. Stat. 18(1), 50-60 (1947).

Igor Ogashawara is a $\mathrm{PhD}$ student at the Department of Earth Science, Indiana UniversityPurdue University Indianapolis. He received his BS degree in geography from São Paulo State University (UNESP), Brazil, in 2012, and his MS degree in remote sensing from the National Institute for Space Research, Brazil, in 2014. His current research interests include remote sensing applications to water resources, geographic information systems, and geographic climatology.

Lin Li is an associate professor at the Department of Earth Sciences, Indiana University-Purdue University Indianapolis.

Max Jacobo Moreno-Madriñán is an assistant professor at Indiana University, Fairbanks School of Public Health. He earned his PhD in environmental health from the University of South Florida School of Public Health and completed a postdoctoral fellowship at the NASA Marshall Space Flight Center. His research uses remote sensing to understand the environmental determinants of vector transmitted and neglected diseases and to the study of the relationship between surface water quality and land use. 